\title{
Social Capital Capacity as Prediction of Dengue Control
}

\author{
Heru Subaris $^{1}$, Subiyanto ${ }^{2}$, Drajat Tri Kartono ${ }^{3}$, Eny Lestary ${ }^{4}$ \\ ${ }^{1}$ Graduate Student of Sebelas Maret University, Indonesia \\ ${ }^{2}$ Medicine Faculty of Sebelas Maret University, Indonesia \\ ${ }^{3}$ Social Politic Faculty of Sebelas Maret University, Indonesia \\ ${ }^{4}$ Doctoral Program of Sebelas Maret University, Indonesia
}

\begin{tabular}{l}
\hline Article Info \\
\hline Article history: \\
Received Nov 9, 2015 \\
Revised Jan 11, 2016 \\
Accepted Feb 11, 2016
\end{tabular}

\section{Keyword:}

Control

Cross sectional

Dengue

Family perception

Larva index

Social capital

\begin{abstract}
The program of elimination of mosquito breeding places is still low since there is no public participation effort in vector control. Social capital is key factor for sustaining any health programs implemented. This study was aimed to analyze the effectiveness of social capital impact on participation and environmental based dengue prevention programs. Study design was cross sectional. Population study was community around Bantul district. Sample was collected as 600 house hold divide on two categories endemic and potential areas. Data was collected with interviews and observation. Data were analyzed with person correlation, confirmatory analyzed and path way analyzed. There were significantly relationships between social capital and family perception, disease perception, individual perception, environment perception and larva density $\mathrm{p}<0.05$. Relationship between perception of counseling and family perception, dengue programs and family perception $\mathrm{p}$ $<0.05$, and the strongest factor is environment participation $(\mathrm{r}=0.296)$. Based on the path analysis for potential areas, social capital was effectively for increased larvae free index through family perception. Theoretically, model for social capital is more efficient in increasing the number of free larvae index through community environment participation. In potential areas, social capital is concluded to be more effectively increase of larva index through participation of individuals. In endemic areas, that dengue programs increase larva index more effectively, compared with social capital does. Strengthening of social capital is important because it effectively the coverage of larva index through environment participation both areas.
\end{abstract}

Copyright $\odot 2016$ Institute of Advanced Engineering and Science. All rights reserved.

\section{Corresponding Author:}

Heru Subaris,

Graduate Student of Sebelas Maret University, Surakarta, Indonesia.

Email: kherusubaris@gmail.com

\section{INTRODUCTION}

Approximately 2.5 billion people are at risk of contracting dengue in the more than 100 tropical and subtropical countries where Aedes aegypti mosquito is found. More than $70 \%$ of this population, or 1.8 billion people, live in countries in Asia and Pacific Regions. Each year there are about 50 million to 100 million cases of dengue fever and 500,000 cases of severe dengue, resulting in hundreds of thousands of hospitalizations and over 20,000 deaths [1]. In Indonesia, dengue disease continues to increase and expand to more than 350 counties or cities [2], and in 2010 it has been expanded to 464 counties/cities [3].

Indonesian government had made efforts to control dengue, such as spraying, larvaciding, eradicating dengue breeding place, even though the results are still not as expected [2]. The success of the program of elimination of mosquito breeding places is still low since there is no public participation effort in vector control. Therefore, reducing dengue related to community participation is one of the government's concerns. 
The government of Indonesia had made dengue control programs which are related with community such as vector control with promotion aspects. But, none of the promotion programs involving community participation. Therefore, for the community, the programs are not interesting to be participated in. Community participation is main role of health program, especially for dengue program. Public participation is a key factor for the programs to be success and sustainable among community process [4]. Previous study was concluded that low public participation makes one particular program is not sustainable. Participation of public is the main key in community mobilization for dengue control program [5].

More strategies, approaches and other programs for controlling dengue were implemented, but it is difficult to be applied because of low community participation. Social capital can be built through the various levels, namely at the level of micro, messo and macro. Previous study was stated that social capital becomes one of the alternatives to solve health, poverty, and economic problems [6], [7].

Various efforts to increase community participation through increased social capital have been done but the programs cannot last longer. Be interested in application of social capital are more effective in solving various problems in society, especially in the prevention of dengue fever [8]. Social capital of the community is a key factor for sustaining any health programs implemented into the community. This study was aimed to analyze the effectiveness of social capital impact on participation and environmental based dengue prevention programs.

\section{RESEARCH METHOD}

Research was used cross sectional design. Population study is community around Bantul district especially of house hold level as 254.149 house hold. Sample was collected with purposive sampling as 600 house hold sampling divide on two categories first endemic areas and second potential areas. For endemic area was collected as try village as divide 180 sample, for potential areas as seven village as divide 420 sample.

Data was collected with interviews to house hold and observation. Instrument devides social capital, family perception, program perception, disease perception, house hold participation, environment participation, Dengue density and container index. Instrument was test for validity and reliability before applied on field. Validity and reliability was done for 225 subjects. Data is shown with table, figure and narration. Data were analyzed with person correlation, confirmatory analyzed and path way analyzed with significant level $95 \%$ confidence interval.

\section{RESULTS AND ANALYSIS}

Based on the analysis of social components, promoting perception program, and dengue program for prevention of dengue disease indicator such as pupa and larvae free indexes; the results are as shown in Table 1.

Table 1. Correlations between Social Capital and Family Perception, Disease Perception, Individual Participation, Environment Participation, Pupa and Larvae Free Index and Container Index

\begin{tabular}{llccccc}
\hline \multirow{2}{*}{ No Variables } & \multicolumn{5}{c}{ Social capital (X2) } \\
\cline { 3 - 7 } & & MS1 & MS2 & MS3 & MS4 & MS5 \\
\cline { 3 - 6 } & & $\mathrm{r}$ & $\mathrm{r}$ & $\mathrm{r}$ & $\mathrm{r}$ & $\mathrm{r}$ \\
\hline 1 & Family perception (X5) & 0.714 & 0.254 & 0.741 & 0.699 & 0.675 \\
2 & Disease perception (X6) & 0.355 & 0.342 & 0.313 & 0.289 & 0.330 \\
3 & Participation (X7) & & & & & \\
& 3 M & 0.570 & 0.147 & 0.754 & 0.664 & 0.593 \\
& Abate & 0.380 & 0.496 & 0.164 & 0.125 & -0.015 \\
& Fish rearing & 0.000 & -0.067 & 0.064 & 0.063 & 0.152 \\
& Garbage management & 0.614 & 0.305 & 0.665 & 0.647 & 0.423 \\
4 & Environment participation (X8) & 0.811 & 0.548 & 0.643 & 0.485 & 0.440 \\
5 & Larvae Density & & & & & \\
& Larvae free index & 0.472 & 0.427 & 0.314 & 0.173 & 0.202 \\
& CI & 0.137 & 0.134 & 0.094 & 0.098 & 0.056 \\
\hline
\end{tabular}

Table 1 shows that family perception indicator that have the strongest relationship is mutual trust $(r=0.741)$, disease perception the strongest is rule compliance indicator $(r=0.355)$, family participation the strongest is mutual trust indicator $(\mathrm{r}=0.754)$. Based on the variable of larvae density, it is known that social capital at indicators of rule compliance, role, mutual trust, mutual relationships and participation are 
significantly correlate with larvae free index $(\mathrm{p}=<0.05)$, where the rule compliance is the strongest one $(\mathrm{r}=0.472)$.

In terms of counseling perception variables, significant correlations are found with family perception, disease perception, individual participation, community participation, larva free index and container index $(\mathrm{CI})$.

Table 2 shows that family perception strongest indicator is the method one $(r=0.784)$, for disease perception strongest as method indicator $(r=0.454)$, individual participation was strongest for method indicators 0,729. Environment participation was strongest is media indicators $r=0,656$, for larvae free index was strongest is media indicators $r=0,317$ and container index was strongest is method indicator.

Table. 2. Correlations between Counseling Perception and Family Perception, Disease Perception, Individual Participation, Environment Participation, Larva Free Index and Container Index

\begin{tabular}{llcccc}
\hline \multirow{2}{*}{ No Variables } & & \multicolumn{3}{c}{ Counseling perception (X3) } \\
\cline { 3 - 6 } & & contents & Method & Media & Counselor \\
\cline { 3 - 6 } & & $\mathrm{r}$ & $\mathrm{r}$ & $\mathrm{r}$ & $\mathrm{r}$ \\
\hline 1 & Family perception (X5) & 0.662 & 0.784 & 0.648 & 0.706 \\
2 & Disease perception (X6) & 0.395 & 0.454 & 0.303 & 0.266 \\
3 & Participation (X7) & 0.661 & 0.729 & 0.596 & 0.689 \\
& 3 M & 0.044 & 0.184 & 0.329 & 0.021 \\
& Abate & 0.042 & 0.040 & 0.024 & 0.097 \\
& Fish rearing & 0.564 & 0.655 & 0.607 & 0.560 \\
& Garbage management & 0.399 & 0.617 & 0.656 & 0.418 \\
4 & Environment participation (X8) & & & & \\
5 & Larvae Density & 0.182 & 0.296 & 0.317 & 0.114 \\
& Larvae free index & -0.058 & -0.105 & -0.045 & -0.19 \\
\hline
\end{tabular}

Table 3 shows that family perception, disease perception and larva index higher Jumantik than Gertak, in other hand for environment participation for both is same. For individual participation $3 \mathrm{M}$ aspect, abate, fish rearing and garbage management higher Jumantik than Gertak.

Table 3. Correlations between Dengue Programs DBD Family Perception, Disease Perception, Individual Participation, Environment Participation, Larva Free Index and Container Index

\begin{tabular}{llcc}
\hline \multirow{2}{*}{ No } & & \multicolumn{2}{c}{ Dengue programs (X4) } \\
\cline { 3 - 4 } & & Jumantik & Gertak \\
\cline { 3 - 4 } & & 0.260 & $\mathrm{R}$ \\
\hline 1 & Family perception (X5) & 0.168 & 0.197 \\
2 & Disease perception (X6) & & 0.126 \\
3 & Participation (X7) & 0.149 & \\
& 3 M & 0.217 & 0.109 \\
& Abate & -0.082 & 0.212 \\
& Fish rearing & 0.176 & -0.038 \\
& Garbage management & 0.296 & 0.173 \\
4 & Environment participation (X8) & & 0.296 \\
5 & Larvae Density & 0.163 & \\
& Larva free index & 0.023 & 0.158 \\
& CI & & -0.048 \\
\hline
\end{tabular}

Path analysis in potential areas was conducted for factors related with the coverage of larvae free index and container index, such as social capital, counseling promotion perception, dengue program perception, individual perception, disease perception, individual participation and environment participation. The results of the analysis are shown in Figure 1. 


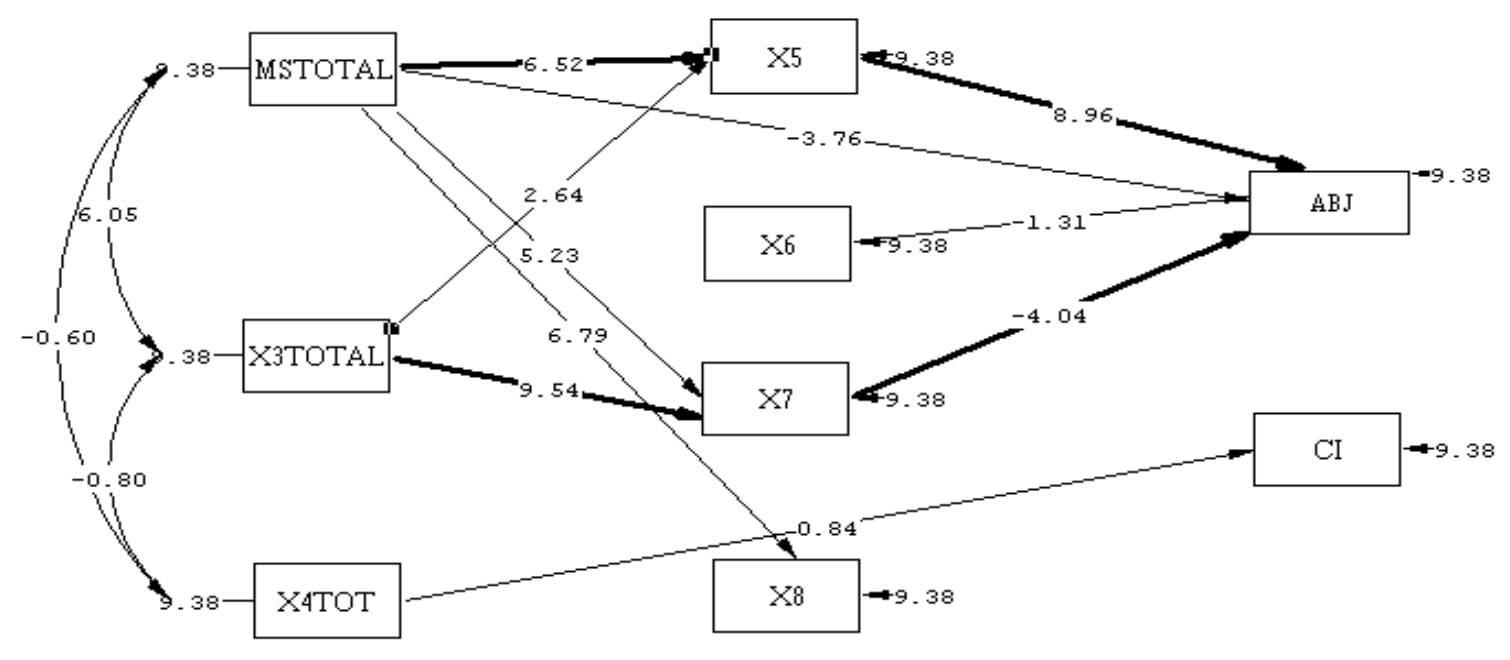

Chi-Square=134.00, df=7, P-value=0.00000, RMSEA=0.321

Figure 1. Paths of social capital, counseling promotion perception, and dengue programs on the coverage of larvae free index and container index at potential areas

The analysis results show that social capital significantly affects family perception $(t=6.52)$, individual participation ( $\mathrm{t}=5.23)$, and environment participation ( $\mathrm{t}=6.79)$. Perception of counseling promoting significantly affects family perception $(\mathrm{t}=2.64)$ as well as individual participation $(\mathrm{t}=9.54)$. Dengue programs is not significant affecting family perception, disease perception, individual participation and environment participation, which can be seen from $t<1.9$. Family perception and individual participation significantly affect the coverage of larvae free index $(t>1.9)$.

Based on the path analysis it can concluded that for potential areas, social capital is effective to increase the larvae free index through family perception, rather than through other factors. Figure 2 is the results of path analysis for endemic areas.

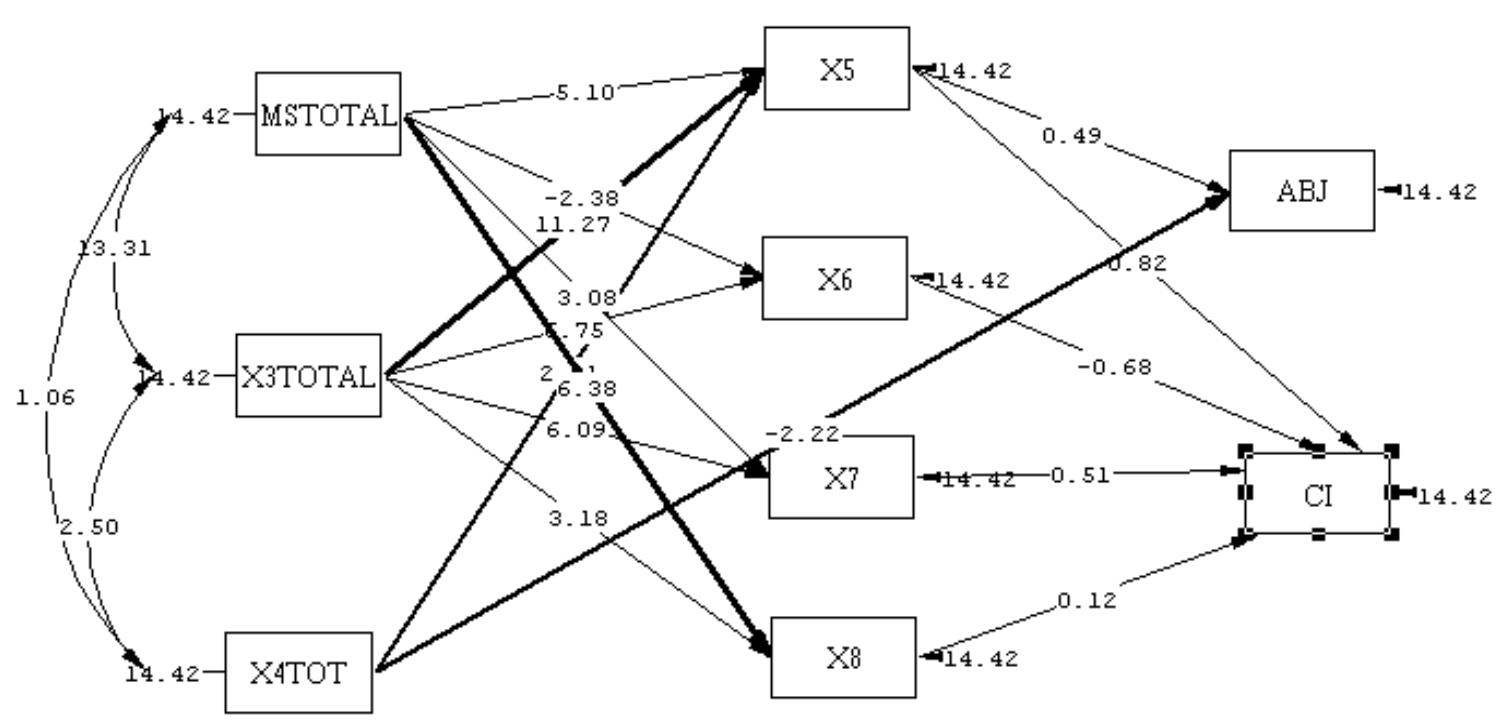

Chi-Square=96.72, df=7, P-value=0.00000, RMSEA=0.176

Figure 2. Paths of social capital, counseling promotion perception, and dengue programs on the coverage of larva free index and container index at endemic areas 
Results of path analysis in endemic areas show that social capital contributes more to environmental participation $(\mathrm{t}=6.38)$ compared with family participation $(\mathrm{t}=3.08)$, family perception $(\mathrm{t}=5.10)$ and disease perception $(\mathrm{t}=-2.38)$ do.

Perception of counseling contributes more to family perception $(\mathrm{t}=11.27)$ than disease perception $(\mathrm{t}=6.75)$, individual participation $(\mathrm{t}=6.09)$ and environment participation $(\mathrm{t}=3.18)$ do. Dengue programs significantly affect individual perception and directly affect the coverage of larva free index. Based on the path analysis it can be identified that social capital and counseling perception do not significantly affect the coverage of larvae free index and container index, but dengue programs directly and significantly affect the coverage of larvae free index. It means that in endemic areas, intervention that is more effective to be implemented is dengue program because it can directly affect larvae free index coverage. Based on the analysis in both endemic and potential areas, the results are shown in Figure 3.

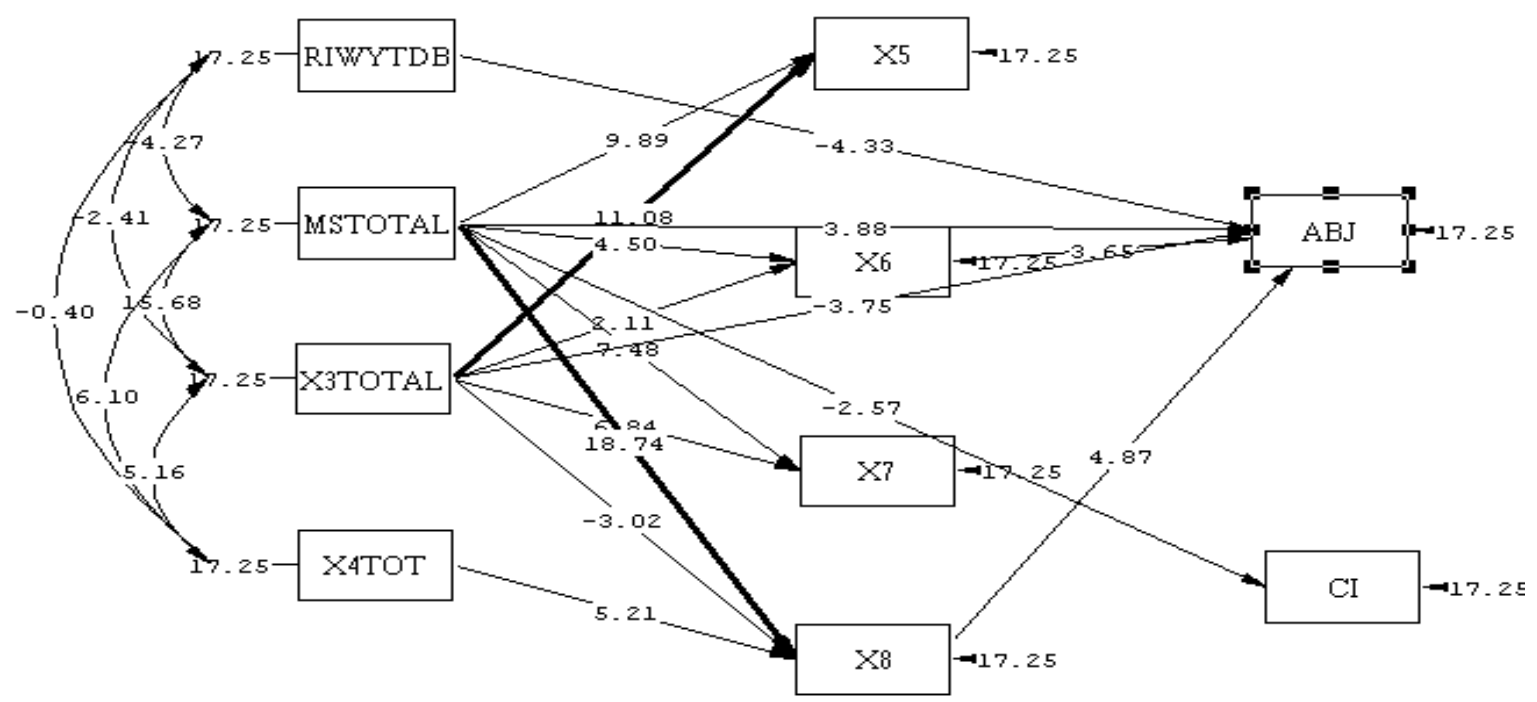

Chi-Square=216.12, df=7, P-value=0.00000, RMSEA=0.224

Figure 3. Theoretical path model results based on variables of dengue history, social capital, counseling and dengue program

Based on the results of the path analysis it can be concluded that dengue history is significant to affect larvae free index directly $(\mathrm{t}=-4.33)$. Social capital significantly affects $\mathrm{X} 5(\mathrm{t}=9.89), \mathrm{X} 6(\mathrm{t}=4.50), \mathrm{X} 7$ $(\mathrm{t}=7: 48)$ and $\mathrm{X} 8(\mathrm{t}=18.74)$, larvae free index $(\mathrm{t}=3.88)$ and container index $(\mathrm{t}=-2.57)$. Counseling significantly affects X5 $(\mathrm{t}=11: 08), \mathrm{X} 6(\mathrm{t}=2.11), \mathrm{X} 7(\mathrm{t}=6.84), \mathrm{X} 8(\mathrm{t}=-3.02)$ and larvae free index $(\mathrm{t}=-3.75)$. Dengue programs are significant in influencing community participation $(\mathrm{X} 8)(\mathrm{t}=5.21)$. Environmental participation (X8) significantly affects larvae free index $(\mathrm{t}=4.87)$. Family perception (X6) significantly affects larva free index $(\mathrm{t}=3.65)$. Theoretically, models for social capital are more efficient in increasing the number of free larvae index through community environment participation. Based on the gap between the theoretical and the empirical ones, the chi-square value is obtained as much as 216.12 , which means the gap between the theoretical and the empirical is significant.

\subsection{Discussion}

In endemic areas the ability of social capital tend to be lower than that in potential areas. This situation occurs because in the region under study the potential areas have social capital better than that in the endemic area. Endemic areas have lower average because of the condition of the elements for bringing up the social capital itself. Social capital is a fundamental aspect in the formation of the existing situation in the community.

Social capital can be appear as structural social capital and cognitive social capital. The second role of social capital is important in efforts to community participation to the environment because people will have solidarity with the state of the surrounding environment, especially in communities who are experiencing or suffering from dengue. 
Previous study mentioned that cognitive social capital in the community can be in the form of norms of trust, solidarity and reciprocity [9]. Social capital refers to the structural composition, scope and activities of local level institutions and networks. Previous study stated that the structural social capital refers to what people do, whereas cognitive social capital refers to what people feel related to social relationships. Social capital in society is an opened network among citizens who occupy the surrounding environment. Social networks are good for a community and are the strength for helping in addressing the issues among the community environment itself through participation [10].

Social networks are formed by bonding, bridging and linking. A bonded social capital is characterized by a strong bondingg of the network to strengthen the identity and common function as a source of help and support among members. Bonding is sourced from family ties as well as from neighbours and friends [11].

A bridged social capital is formed from the interaction between groups in particular area such as religious, ethnicity, or certain income level groups. A linked social capital is generally formed from a formal relationship between various parties such as political institutions, banks, health clinics, schools, agriculture, and tourism.

Individual social capital can affect the health and health behaviours in a positive way through social support, social influence, social participation, and access to material resources. The study shows that in potential areas the community social capital tends to be better than that in the endemic areas. This situation is emerged because in endemic areas community participation is relatively lower compared with that in potential areas.

Community eenvironment participation affects larva free index because active environment participation such as environmental hygiene will break the mode of transmission of dengue fever vector. Dengue vectors can not evolve quickly in the regions which have not been experienced the development of those vector. Previous study mentioned that the principle preventive action of dengue is to manage of environment. Compared with other factors, environment, which is consisted of host environment and vector environment, influences more in the development of dengue fever. Blum argued that environment factor is important for disease prevention, thus interventions management related to environment has more priority. This is especially works for dengue that its preventive measure related with addressing environment management [3].

Based on path analysis, it come to conclusion that social capital is effectively decreased the larva index through environment participation rather than through family perception, disease perception and individual perception. It is because the transmission of dengue is related with mosquito vector, so that the intervention is more effective with environment participation compared with those three perceptions.

Family perception, disease perception and individual perception were addressing more the dengue problem in communities which has ever experiencing the disease history beforehand. Individuals who experienced the disease tend to have high environment participation, and in other hand, those who never get dengue have low participation in the environment.

Based on the results, it is revealed that endemic areas are low in environment participation compared with potential areas. It is can be concluded that environment participation has fundamental role to disconnect the mode of dengue vector transmission. Environment participation help the various government programs related to dengue controlling. Government programs without the support of community participation tend to be meaningless because the community had no involvement in the eradication of the diseases so that the existing programs tend to not running well.

Dengue programs tend to be more sustainable if the community involvement has particular role in the program activities. Government dengue programs also can be more sustainable if the community is involved directly along with their behaviourss. This situation requires an approach that the community is treated both as subject and object. The community aapproach can be by means of the roles of community leaders, religious leaders, or institutions that are within the scope of the community.

It is concluded that public participation efforts tend to be more successful through bridging and linking methods of social capital. Bridging method focus in involving community leaders, meanwhile the focus of linking method is at involving the role of both formal and non-formal institutions in the society. Dengue control program requires a clear and integrated approach with strong community involvement. Community leaders are effective channel for disseminating information and educating the public as well as encouraging change at household level.

Based on the path model it is found that social capital is more effective in lowering the container index through participation compared to family perception, disease perception, and individual perception do. The circumstances that led to participation of good environment can reduce container index through movement of community by utilizing the existing networking among the community. Social capital is seen as an individual characteristic and can contribute to health promotion by adding new knowledge about how the 
social network best interventions [12]. Social capital is source for contributing to the welfare of individuals and society. There are four models of approaches used in problem solving, i.e. economic capital, human capital, natural capital and social capital [13].

Social capital is more able to reduce larva index than to reduce container index through community participation. It is because social capital has implication for environment rather than for individual and family participation. Social capital is more likely to correspond with problems related to the community in general rather than the problems of an individual nature. The decrease of container index is more oriented on circumstances of individuals and families. Measures related to environment is more appropriate approach to social cohesion, in contrast, efforts related to individuals and families is more appropriate approach to social networking [8]. Social cohesion move of people rely on aspects of the participation of community leaders involved in the community through existing networks, while social networks are more reliant on role of individuals and families through the move of community. It is because social capital are more likely to affect larva index rather than to container index.

\section{CONCLUSION}

In potential areas, social capital is concluded to be more effectively increase the coverage of larva index through participation of individuals. So that, appropriate interventions that have to be applied in potential areas are in the form of strengthening social capital regulations and roles of community leaders, and the strengthening of relations between communities, as well. In endemic areas, it is concluded that dengue programs increase larva index more effectively, compared with social capital does. Strengthening of social capital is important because it effectively improves the coverage of larva index through environment participation both in endemic and potential areas.

\section{REFERENCES}

[1] WHO, "Situation Of Dengue/Dengue Haemorrhagic Fever In the South-East Asia Region: Prevention And Control Status In SEA Countries", 2006.

[2] Indonesia Department, "Development and Future Challenges in Health Promotion in Indonesia", Jakarta, Departemen Kesehatan RI, 2009.

[3] Sumantri, A., "Environmental Based Prevention Model on The Dengue Haemorhagic Fever Dissemination in The DKI Jakarta Province", Journal of Natural Sciences Research, vol/issue: 2(3), 2012.

[4] Nadesul, H., "Easy Ways to Beat Dengue", Jakarta, Book Publishers Compass, 2007.

[5] Dalton, JH., Elias, MJ., Wandersman, A., "Community Psychology: Linking Individuals and Communities", Australia, Wadsworth, 2001.

[6] Miller LD., Scheffler R., Lam S., Rosenberg R., Rupp A., "Social Capital and Health in Indonesia. Robert Wood Johnson Foundation and WHO for Financial Support", 2006.

[7] Brata, AG., "Social Capital and Credit in A Javanese Village", Research Institute University of Atmajaya Yogyakarta, 2004.

[8] Eriksson, M., "Social Capital, Health and Community Action - Implication for Health Promotion, Sweden, Umea University, 2010.

[9] Krishna, A., Sharder, E., "Cross-Cultural Measures Social Capital: a tool and Results from India and Panama. Social Capital Initiative", Working Paper N0.21. Washington D.C. The World Bank, 2000.

[10] Harpham T., Grant E., Thomas E., "Measuring Social Capital within Health Surveys: key issues", Health Policy Plan, vol. 17, pp. 106-11, 2002.

[11] Putnam RD., "Making Democracy Work: Civic Traditions in Modern Italy", Princeton, Princeton University Press, 1993.

[12] Eriksson, U., "Healt Outcomes among Swedish Children: the Role of Social Capital in the Family, School and Neighbourhood", BMC Public Health, vol. 12, pp. 628, 2013. http://www.biomedcontrol.com/471248/19628.

[13] Edwards, "Measuring Social Capital: an Australian Framework and Indicators", Australia, Australian Bureau of Statistics, ISBN 0664247937 2, 2004. 